\title{
Student Attitudes towards Chemistry: an Examination of Choices and Preferences
}

\author{
Jassem G. Mahdi* \\ Department of Medical Sciences, College of Medicine, Shaqra University, Saudi Arabia \\ Corresponding author: jmahdi@su.edu.sa \\ Received April 21, 2014; Revised April 28, 2014; Accepted May 26, 2014
}

\begin{abstract}
Chemistry is one of the foundations of science, technology and industry. It forms the fundamentals of the life sciences. This study, aims to investigate what make students choose or not to choose Chemistry and what are the main factors that contribute to the understanding of Chemistry as a subject? Four aspects were used to appraise students' attitudes towards Chemical education, including student's perceptions toward Chemistry, the concept of chemical knowledge and its understanding, application of chemical knowledge and understanding and career, help and school, using a questionnaire technique. Respondents indicated that students were positive with most statements to support their education, despite the perception that Chemistry is a difficult subject. Furthermore, respondents indicated that Chemistry is an interesting and not a boring subject, which certainly demands more attention to raise its status. Having help at home and from teachers were important factors that play significant roles in the student's preference to Chemistry but there is a disfavoured option for various careers, which may hinder student's interest in Chemistry.
\end{abstract}

Keywords: Chemistry, education, perception, concepts, college, quantitative approach

Cite This Article: Jassem G. Mahdi, "Student Attitudes towards Chemistry: an Examination of Choices snd Preferences.” American Journal of Educational Research, vol. 2, no. 6 (2014): 351-356. doi: 10.12691/education2-6-3.

\section{Introduction}

Chemistry is one of the main subjects that encompass valuable activities. Nonetheless, many instructors and learners consider Chemistry difficult to teach and to study. It plays an important role in the socio-economic development of various industries, including pharmaceuticals and petrochemicals. Chemistry, also is a requirement to study medicine, pharmacy and environment. However, the rate of student enrolment at college and university has been reported to be declined since 1993 in Britain $[1,2,3]$. Therefore, the aim of this study is to analyse the student's choices and preferences in studying Chemistry at Advanced Subsidiary (AS).

\section{Study Rationale}

Chemistry is a supportive subject for various disciplines, including pharmacology, physiology, clinical, chemical industry and environment. It appears from the literature that the general perception of chemical education for many people have been described as challenging and difficult to understand. This may be related to the fact that Chemistry involves different terminologies, structures and calculations. The learning of these elements, for many teachers and students may cause different levels of difficulties. These challenges and difficulties have been addressed in the literature to require a considerable attention [4]. He maintained that chemical education has been in a depressing state for 40 years. He reflected the state of chemical education by quoting the following

I was never any good at Chemistry; I never understood atoms and molecules; I enjoyed splashing about in the laboratory, but I did not understand what I was doing ([4] p. 34).

These and other results were lead the Royal Society of Chemistry (RSC), in their meeting on 22 January 2002, to address the following question: Does Chemistry have a future? [2].

The decline rate of Chemistry at university level may involve intrinsic (self) and/or extrinsic (school, teacher) factors at both the General Certificate of Secondary Education (GCSE) and Advanced level (A-levels) to encourage students undertaking Chemistry subject further. In this respect, many educational institutions recognise the importance of both teacher and student roles in the educational process, whereas, both contribute to the process outcome. Moreover, managing an effective learning process is often complex. Indeed research in the individualising of learning has not come up with a distinct specific technique(s) that can be applied to teaching $[5,6]$. In contrast, researches in the last four decades have studied the elements that are able to support effective learning. The results have indicated that students understanding and application of knowledge (cognitive) should be based on thinking and organisation of knowledge, not on studying hard and practice [6,7]). The 
modern didactic teaching methods that involve demonstrations, modules and simulation are necessary for building up the subsequent levels of interaction. The use of different chemical modules, for example, allows effective individualization of teaching Chemistry, with the aim of promoting an effective learning process [8].

In addition, both internal and external factors can influence the educational process. The quality of the teaching/learning process is the main internal factors while surroundings, business and politics are the main external factors. Although these factors are inter and intraact with each other in a complex manner, the main concern for the negotiated assignment is to analyse the student's perceptions on how they perceive Chemical Education. The effective teaching performance should consider the learning needs of the student's. The other criterion for managing effective learning is to create positive attitudes to learning and establish an assessment approach that reflects the insight of the learning process [5].

The aim of the didactic theory in Chemical Education is to facilitate the appropriate understanding of different aspects in Chemistry. Schooling at different stages follows theoretical models for the purpose of the application of these concepts later in students' perspective professions. The end product of studying must provide a minimum standard for students to apply the pedagogical concept in effective problem-solving. An effective teaching and learning process is most likely to occur when students are able to analyse problems, think critically and communicate their findings. Thus, maximising the educational outcome is not a one-way process, and involves the pedagogical effort and knowledge of teachers and students, at which both are subject to different environments and effectors.

Hence, didactic recourses help to learn Chemistry cognitively and psychometrically. Furthermore, learning Chemistry can also be active when knowledge is organised in a meaningful pattern and reflects a deep understanding of the subject. Therefore, the role of the Chemistry teacher is important as they need to establish an effective learning environment that is relevant to the capabilities of the students to construct their own knowledge. The essence of teaching and learning Chemistry is the ability of the teacher to provide experiences that share their expert meanings with novice learners [9]. These expert meanings include not only concepts, but also knowledge about how to learn Chemistry [9].

\section{Methodology}

The current study adopts the quantitative approach to examine student choices and preferences toward studying Chemistry at AS level. In this approach, the questionnaire technique was used to collect data [10]. This technique possess different advantages, including reliability compared with the interview method, as it is anonymous; it encourages greater honesty, and more economical in terms of time and money $[11,12]$

The construction of the questionnaire was aimed to achieve an effective instrument and establish sound criteria to reflect the aim and purpose of the current study.
In addition, literature indicated that there is no reason why research objectives cannot be achieved if they are formulated before the questionnaire is designed [13].

The questionnaire instrument for this study includes two-section: the independent and dependent variables. Each of them comprised several questions or statements, in closed-ended form. The structure of the questionnaire is described as below:

1. Independent variables section includes three general questions related to student achievements in GCSE Science and whether students are studying Chemistry or not.

2. Dependent variables includes four sets of statements, including student's perceptions into Chemistry, The concept of chemical knowledge and understanding, application of chemical knowledge and understanding, career, help and school.

Respondents were requested to select the appropriate levels for the extent of agreement for 21 statements using three-point scale. The method involved an ascending scale of statement and consequence the agreement which were put in a three-point (i.e. 1- agree; 2- not sure; 3- disagree) scale order.

The sample population was selected according to the belief that they would be able to reflect the broad perspective of the perceptions to chemical education. Therefore, 70 AS students were selected from a population of 164 . The sample population were all AS students at different schools in Cardiff, UK.

70 questionnaire forms were distributed in two ways; via email and in person. MSN Messenger Service was used to encourage students to complete the questionnaire. Only 36 questionnaire forms, or 51.4\%, where returned completed. All data obtained from the questionnaire was transformed into numerical values and fed into the computer using SPSS for Windows, and results were then interpreted statistically. To determine whether variables were statistically significant, the significance level of 0.05 or more were used to indicate the probability of committing a type 1 error of $5 \%$ or less, based on a twotailed test.

\section{Results and Data Analysis}

Results indicated that the mean values ranged between 2.33 (or not sure option) to 1.5 (or agree option). Student perceptions into Chemistry indicated that most students agreed that Chemistry is an interesting subject (statement $3 \mathrm{~A}$; 23 , or $63.9 \%$ ), it involves too many chemical formulas and is difficult to remember (statement 5A, 22, or $61.1 \%$ ) and it is a challenging subject (statement 7A, 21, or \%). 58.3\%). However, responses to other statements in the other 3 sections ( $B, C$ and $D$, Table 1 ) were approximately equally distributed between the three options (agree, not sure and disagree), except in two statements where the majority of students agreed: to apply chemical knowledge and understand familiar and unfamiliar situations require long hours of studying (23, or $63.9 \%$ ) (3C, Table 1), and knowing that there will be a lot of help offered by the teachers and the school helps me to decide whether to take Chemistry (25, or 69.4\%) (5D, Table 1).

Results of the independent variables indicated that most students had B or C or less in their GCSE science exam 
(Table 2). Most of them (14, or 38.9\%) claimed that they did well in Chemistry (Table 1). Respondents were slightly more in favour of students that were not studying Chemistry (19, or 52.8\%) compared to those who are taking Chemistry (17, or $47.2 \%)$ at AS level (Table 2). Most students (24, or $66.7 \%)$ were not planning to carry on studying Chemistry at A2 level (Table 2). These results suggest that student's perceptions were likely to assist in establishing both the necessary background data and the concept related to student choices in choosing to study advanced Chemistry. Results showed students planning to take A2 (12, or $33.3 \%)$ had A-A* grade in GCSE (8, $22.2 \%$ ) (Table 2). Table 1 also shows the overall frequencies and the means of responses concerning the students’ Chemistry education at college level.

Table 1. shows the frequencies, overall mean values and standard deviation of students responses to the 21 statements ( $\mathrm{N}=36)(1-$ agree; 2 - Not sure, 3- disagree)

\begin{tabular}{|c|c|c|c|c|c|}
\hline \\
\hline & & 1 & $2:$ & 3 Mean & Std. Dev \\
\hline $1 \mathrm{~A}$ & Chemistry is an easy subject. & 10 & 71 & 192.3333 & 0.7928 \\
\hline $2 \mathrm{~A}$ & Chemistry is a difficult subject. & 12 & 91 & 152.2500 & 0.8742 \\
\hline 3A & Chemistry is an interesting subject. & 23 & 8 & 52.1667 & 0.8452 \\
\hline $4 \mathrm{~A}$ & The mathematics involved makes it not easy to understand. & 14 & 111 & 112.1111 & 0.8545 \\
\hline $5 \mathrm{~A}$ & There are too many chemical formulas that are difficult to remember. & 22 & 5 & 92.0833 & 0.8742 \\
\hline $6 \mathrm{~A}$ & The practical part of a Chemistry lesson encouraged me to take it. & 19 & 8 & 91.6389 & 0.8333 \\
\hline 7A & Chemistry is a challenging subject that is why I like it. & 21 & 78 & 82.0556 & 0.9840 \\
\hline $8 \mathrm{~A}$ & Chemistry is a boring subject that is why I do not like it. & 7 & 101 & 192.0556 & 0.9241 \\
\hline $1 \mathrm{~B}$ & It is not easy to recall facts, terminology and relationships. & 14 & 111 & 111.9722 & 0.8779 \\
\hline 2B & It is tricky to understand chemical principles and concepts. & 14 & 111 & 111.9444 & 0.8600 \\
\hline 3B & It is difficult to draw on existing knowledge to show an understanding of the responsible use of Chemistry in society. & 14 & 111 & 111.9444 & 0.9241 \\
\hline 4B & It is not easy to select, organise and present chemical information clearly and logically. & 11 & 101 & 151.9167 & 0.8409 \\
\hline $1 \mathrm{C}$ & Explaining and interpreting chemical principles and concepts are not easy. & 14 & 101 & 121.9167 & 0.8409 \\
\hline 2C & Chemistry is a complex subject and data are not easy to present. & 14 & 61 & 161.9167 & 0.8409 \\
\hline 3C & To apply chemical knowledge and understand familiar and unfamiliar situations require long hours of studying. & 23 & 45 & 91.9167 & 0.8409 \\
\hline 4C & It is complicated to make connections between different topics. & 10 & 101 & 161.7222 & 0.8489 \\
\hline $1 \mathrm{D}$ & I considered taking Chemistry because there will be help offered at home. & & 61 & 141.6389 & 0.8333 \\
\hline $2 \mathrm{D}$ & I considered taking Chemistry for a future career. & 16 & 28 & 81.6389 & 0.8669 \\
\hline 3D & The teacher at GCSE built up my interest. & 14 & 91 & 131.6111 & 0.8028 \\
\hline 4D & Having a good teacher persuades me to carry on with Chemistry. & & 87 & 71.6111 & 0.8711 \\
\hline $5 \mathrm{D}$ & $\begin{array}{c}\text { Knowing that there will be a lot of help offered by the teachers and the school helps me to decide whether to take } \\
\text { Chemistry. }\end{array}$ & & 6 & 51.5000 & 0.7368 \\
\hline
\end{tabular}

Table 2. Respondents by GCSE graduates

\begin{tabular}{|c|c|c|c|c|c|c|c|}
\hline \multicolumn{2}{|c|}{ GCSE Grade } & \multicolumn{2}{|c|}{ Achievement } & \multicolumn{2}{|c|}{ Student selection } & \multicolumn{2}{|c|}{ Student planning } \\
\hline Category & Freq.( \%) & Category & Freq. \% & Category & Freq. \% & Category & Freq., \% \\
\hline A-A* & $15(41.7$ & Well & $12(33.3)$ & & & & \\
\hline B & $13(36.1$ & Good & $10(27.8)$ & Yes & 19 (52.8) & Yes & 24, (66.7) \\
\hline $\mathrm{C}$ or less & $8(22.2$ & Poor & 14 (38.9) & No & $17(47.2)$ & No & 12, (33.3) \\
\hline Total & $36(100$ & & 36 (100) & & $36(100)$ & & $36(100)$ \\
\hline
\end{tabular}

Cross-tabulating analyses showed differences (agree/disagree) between the two groups of respondents that are studying or not studying Chemistry over issues related to competence in Chemistry. Table 3 indicates that the majority of students (not studying Chemistry $=11$, or $57.9 \%$, studying Chemistry $=8$, or $47.1 \%$ ) disagreed with the Chemistry is an easy subject statement while the majority of students (12, or $70.6 \%$ ) who are studying
Chemistry disagree on Chemistry is a difficult subject statement (Table 3). Similarly the majority of Chemistry students (16, or 94.1\%) thought that Chemistry is an interesting subject (16, or 94.1\%), easy to understand (9, or $52.9 \%)$, challenging subject (15, or $88.2 \%$ ) and is not $a$ boring subject (14, or $82.4 \%$ ) (Table 3 ). These results may indicate that students have set up their preferences to fit their future planning. 
Table 3. Cross tabulation of are you studying Chemistry as an AS versus dependent statements related to students' perception into Chemistry

\begin{tabular}{|c|c|c|c|c|c|c|}
\hline & & agree & not sure & disagree & Total & Sig. (2-sided)* \\
\hline & & Ch & is an easy & $(1 \mathrm{~A})$ & & \\
\hline \multirow{11}{*}{ Are you studying Chemistry as an AS? } & Yes(\%) & $7(41.2)$ & 2(11.8) & $8(47.1)$ & $17(100)$ & \multirow{2}{*}{0.196} \\
\hline & $\mathrm{No}(\%)$ & $3(15.8)$ & $5(26.3)$ & 11(57.9) & 19(100) & \\
\hline & \multicolumn{5}{|c|}{ Chemistry is a difficult subject (2A) } & \\
\hline & Yes(\%) & $4(23.5)$ & $1(5.9)$ & $12(70.6)$ & $17(100)$ & \multirow{2}{*}{0.002} \\
\hline & $\mathrm{No}(\%)$ & $8(42.1)$ & $8(42.1)$ & $3(15.8)$ & $19(100)$ & \\
\hline & \multicolumn{5}{|c|}{ Chemistry is an interesting subject (3A) } & \\
\hline & Yes(\%) & 16(94.1) & $0(0.0)$ & $1(5.9)$ & $17(100)$ & \multirow{2}{*}{0.001} \\
\hline & No(\%) & $7(36.8)$ & $8(42.1)$ & $4(2.1)$ & $19(100)$ & \\
\hline & \multicolumn{5}{|c|}{ The mathematics involved makes it not easy to understand (4A) } & \\
\hline & Yes(\%) & $4(23.5)$ & $4(23.5)$ & $9(52.9)$ & $17(100)$ & \multirow{2}{*}{0.021} \\
\hline & $\mathrm{No}(\%)$ & $10(52.6)$ & $7(36.8)$ & 2(10.5) & 19(100) & \\
\hline \multirow{12}{*}{ Are you studying Chemistry as an AS? } & There & many che & ormulas tl & ifficult to & er $(5 A)$ & \\
\hline & Yes(\%) & $10(58.8)$ & 2(11.8) & $5(29.4)$ & $17(100)$ & \\
\hline & $\mathrm{No}(\%)$ & $12(63.2)$ & $3(15.8)$ & $4(21.1)$ & $19(100)$ & \multirow{2}{*}{0.826} \\
\hline & \multicolumn{5}{|c|}{ The practical part of a Chemistry lesson encouraged me to take it (6A) } & \\
\hline & Yes(\%) & 14(82.4) & $3(17.6)$ & -- & 17(100) & \\
\hline & $\mathrm{No}(\%)$ & $5(26.3)$ & $5(26.3)$ & $9(47.4)$ & $19(100)$ & \multirow{2}{*}{0.001} \\
\hline & \multicolumn{5}{|c|}{ Chemistry is a challenging subject that is why I like it (7A) } & \\
\hline & Yes(\%) & 15(88.2) & $1(5.9)$ & $1(5.9)$ & $17(100)$ & \\
\hline & $\mathrm{No}(\%)$ & $6(31.6)$ & $6(31.6)$ & $7(36.8)$ & 19(100) & \multirow{2}{*}{0.003} \\
\hline & \multicolumn{5}{|c|}{ Chemistry is a boring subject that is why I do not like it (8A) } & \\
\hline & Yes(\%) & $1(5.9)$ & 2(11.8) & $14(82.4)$ & 17(100) & \multirow{2}{*}{0.003} \\
\hline & No(\%) & $6(31.6)$ & $8(42.1)$ & $5(26.3)$ & 19(100) & \\
\hline
\end{tabular}

*Pearson Chi-Square value respectively = 3.258, 12.104, 13.252, 7.757, 0.383, 13.694, 11.854, 11.359; degree of freedom for all = 2

Table 4 shows students perceptions into 4 statements related to the concept of chemical knowledge and understanding. The majority of students again have different views into Chemistry where students that are taken Chemistry were positive with the difficulty of Chemistry as a subject while students that are not studying Chemistry reflected negative views and, to a certain extent, thought Chemistry was a difficult subject. Responses to It is not easy to recall facts, term terminology and relationships indicated that there were 10 students not studying AS Chemistry who were positive to this statement. In contrast, 8 students or $47.1 \%$ of the students that are studying Chemistry were negative to statement $1 \mathrm{~B}$ (Table 4). Results of responses into the other statements in this table show similar results.

Table 4. Cross tabulation of 'are you studying Chemistry as an AS' versus dependent statements related to 'the concept of chemical knowledge and understanding'

\begin{tabular}{|c|c|c|c|c|c|c|}
\hline & & agree & not sure & disagree & Total & Sig. (2-sided)* \\
\hline & \multicolumn{6}{|c|}{ It is not easy to recall facts, terminology and relationships (1B) } \\
\hline \multirow{11}{*}{$\begin{array}{l}\text { Are you studying Chemistry as an } \\
\text { AS? }\end{array}$} & Yes(\%) & $4(23.5)$ & $5(29.4)$ & $8(47.1)$ & 17(100) & \multirow{2}{*}{0.089} \\
\hline & No (\%) & $10(52.6)$ & $6(31.6)$ & $3(15.8)$ & 19(100) & \\
\hline & \multicolumn{6}{|c|}{ It is tricky to understand chemical principles and concepts (2B) } \\
\hline & Yes(\%) & $6(35.3)$ & $4(23.5)$ & $7(41.2)$ & 17(100) & \multirow{2}{*}{0.403} \\
\hline & No $(\%)$ & $8(42.1)$ & $7(36.8)$ & $4(21.1)$ & 19(100) & \\
\hline & \multicolumn{6}{|c|}{$\begin{array}{c}\text { It is difficult to draw on existing knowledge to show an understanding of the responsible use of Chemistry in } \\
\text { society (3B) }\end{array}$} \\
\hline & Yes(\%) & 5 & $4(23.5)$ & $8(47.1)$ & 17(100) & \multirow{2}{*}{0.126} \\
\hline & No (\%) & $9(47.4)$ & $7(36.8)$ & $3(15.8)$ & 19(100) & \\
\hline & \multicolumn{6}{|c|}{ It is not easy to select, organise and present chemical information clearly and logically (4B) } \\
\hline & Yes(\%) & $3(17.6)$ & $1(5.9)$ & $13(76.5)$ & 17(100) & \multirow{2}{*}{0.000} \\
\hline & No (\%) & $8(42.1)$ & $9(47.4)$ & 2(10.5) & 19(100) & \\
\hline
\end{tabular}

** Pearson Chi-Square value respectively = 4.839, 1.817, 4.135, 16.680; degree of freedom for all = 2

Furthermore, Responses into the statements related to the application of chemical knowledge and understanding showed the same trend of answers in Tables (5). The majority of students in the two groups (studying or not studying Chemistry) also showed different views except for to apply chemical knowledge and understand familiar and unfamiliar situations require long hours of studying statement. Student in both groups showed positive views (Studying Chemistry $=10$, or $58.8 \%$, and not studying Chemistry $=13,68.4 \%$ ). 
Table 5. Cross tabulation of 'are you studying Chemistry as an AS' versus dependent statements related to Application of Chemical Knowledge and Understanding

\begin{tabular}{|c|c|c|c|c|c|c|}
\hline \multirow{13}{*}{$\begin{array}{l}\text { Are you studying Chemistry as an } \\
\qquad \text { AS? }\end{array}$} & & agree & not sure & disagree & Total & Sig. (2-sided)* \\
\hline & \multicolumn{6}{|c|}{ Explaining and interpreting chemical principles and concepts are not easy (1C) } \\
\hline & Yes (\%) & $4(23.5)$ & $3(17.6)$ & $10(58.8)$ & $17(100)$ & \multirow{2}{*}{0.009} \\
\hline & No (\%) & $10(52.6)$ & $7(36.8)$ & $2(10.5)$ & $19(100)$ & \\
\hline & \multicolumn{6}{|c|}{ Chemistry is a complex subject and data are not easy to present (2C) } \\
\hline & Yes (\%) & $3(17.6)$ & $4(23.5)$ & $10(58.8)$ & $17(100)$ & \multirow{2}{*}{0.046} \\
\hline & No (\%) & 11(57.9) & $2(10.5)$ & $6(31.6)$ & 19(100) & \\
\hline & \multicolumn{6}{|c|}{$\begin{array}{l}\text { To apply chemical knowledge and understand familiar and unfamiliar situations require long hours of studying } \\
\text { (3C) }\end{array}$} \\
\hline & Yes (\%) & 10(58.8) & $1(5.9)$ & $6(35.3)$ & $17(100)$ & \multirow{2}{*}{0.000} \\
\hline & No (\%) & - & $3(15.8)$ & $3(15.8)$ & 19(100) & \\
\hline & \multicolumn{6}{|c|}{ It is complicated to make connections between different topics (4C) } \\
\hline & Yes (\%) & $0(0.0)$ & $4(23.5)$ & 13(76.5) & 17(100) & \multirow{2}{*}{0.000} \\
\hline & No (\%) & $10(52.6)$ & $6(31.6)$ & $3(15.8)$ & 19(100) & \\
\hline
\end{tabular}

* Pearson Chi-Square value respectively = 9.423, 6.146, 2.287, 16.590; degree of freedom for all $=2$

Table 6 includes the results of five statements related to teacher and school in helping to decide whether to take career, help and school. The cross-tabulation analysis of most of these issues is consistent with the overall perceptions into the issues mentioned and analysed in the previous three tables. The vast majority of AS Chemistry students (13, or $76.5 \%)$ agreed in the importance of help that they may receive at home. Likewise, students agreed that they are taking Chemistry for their future careers and the role of the teacher at GCSE level in building up their interest in Chemistry. Furthermore, both groups of students agree with the importance of the role of both

Chemistry.

The above results in the four sections of the dependents variables have clearly showed that students differ in their views related to Chemistry education. The overall responses to the 21 statements also showed that between $2-11 \%$ of the students responded to statements by not sure while $3-7 \%$ of the minority of students in each group have taken the same view of the other group (studying/not studying Chemistry).

Table 6. Cross tabulation of statement 'are you studying Chemistry as an AS' versus dependent statements related to Career, help and School

\begin{tabular}{|c|c|c|c|c|c|c|}
\hline & & agree & not sure & disagree & Total & Sig. (2-sided)* \\
\hline \multirow{6}{*}{$\begin{array}{l}\text { Are you studying Chemistry as } \\
\text { an AS? }\end{array}$} & \multicolumn{6}{|c|}{ I considered taking Chemistry because there will be help offered at home (1D) } \\
\hline & Yes (\%) & $13(76.5)$ & 1(5.9) & $3(17.6)$ & $17(100)$ & \multirow{2}{*}{0.001} \\
\hline & No (\%) & $3(15.8)$ & $5(26.3)$ & $11(57.9)$ & 19(100) & \\
\hline & \multicolumn{6}{|c|}{ I considered taking Chemistry for a future career (2D) } \\
\hline & Yes (\%) & $11(64.7)$ & $1(5.9)$ & $5(29.4)$ & $17(100)$ & \multirow{2}{*}{0.057} \\
\hline & No (\%) & $5(26.3)$ & $1(5.3)$ & 13(68.4) & 19(100) & \\
\hline \multirow{9}{*}{$\begin{array}{l}\text { Are you studying Chemistry as } \\
\text { an AS? }\end{array}$} & \multicolumn{6}{|c|}{ The teacher at GCSE built up my interest (3D) } \\
\hline & Yes (\%) & $8(47.1)$ & 6(35.3) & $3(17.6)$ & $17(100)$ & \multirow{2}{*}{0.0871} \\
\hline & No (\%) & $6(31.6)$ & $3(15.8)$ & $10(52.6)$ & 19(100) & \\
\hline & \multicolumn{6}{|c|}{ Having a good teacher persuades me to carry on with Chemistry (4D) } \\
\hline & Yes (\%) & $9(52.9)$ & $4(23.5)$ & $4(23.5)$ & $17(100)$ & \multirow{2}{*}{0.462} \\
\hline & No (\%) & $12(63.2)$ & $4(21.1)$ & $3(15.8)$ & 19(100) & \\
\hline & \multicolumn{6}{|c|}{$\begin{array}{l}\text { Knowing that there will be a lot of help offered by the teachers and the school helps me to decide whether to take } \\
\text { Chemistry (5D) }\end{array}$} \\
\hline & Yes (\%) & $14(82.4)$ & $1(5.9)$ & $2(11.8)$ & $17(100)$ & \multirow{2}{*}{0.215} \\
\hline & No (\%) & 11(57.9) & $5(26.3)$ & $3(15.8)$ & $19(100)$ & \\
\hline
\end{tabular}

*Pearson Chi-Square value respectively = 13.418, 5.712, 4.959, 0.462, 3.125

\section{Discussion and Conclusion}

The results of the questionnaire in the previous section attempted to answer the research question in the title: Why do students like to study Chemistry? The data was derived from 36 respondents out of 70 questionnaire sheets that were distributed to AS students at different schools in Cardiff. The results include four independent and twenty one dependent variables related to four aspects: (1)students' perceptions into Chemistry, (2)- the concept of chemical knowledge and understanding, (3)- application of chemical knowledge and understanding and (4) career, help and school. Cross-tabulation analysis was used to investigate students' perception according to whether they were studying Chemistry or not.
Responses to different statements were analysed by cross-tabulation of the subject preference (i.e. are you studying Chemistry as an AS? (Yes or No) and the responses to the twenty-one statements. Both frequencies and percentages were used to express and discuss the results. Although, results of the cross-tabulation showed clear distinction in student's options in the 3-point scale, chi-square analysis confirmed the statistical differences between subject preferences on most issues (Table 3Table 6). Generally cross-tabulation analysis indicated that students studying Chemistry were positive with the relevant statements, while students who chose not to study AS Chemistry were negative towards relevant issues. Perhaps, this reflects the students' awareness to what they chose to study to support their future plan or according to what they can do. The differences in the perceptions of 
students to chemical education were confirmed by chisquare as shown in Table 7. Results of chi-square showed that students were significantly differed on 10 statements, or $47.6 \%$ of the total statements $(\mathrm{N}=21)$.

These results indicated that students studying AS Chemistry were significantly different in their perceptions from their peers who were not studying Chemistry. However, the majority of both groups thought that Chemistry is not an easy subject to study. This may be a wide held view amongst other students who have not participated in this study. Some students have to take Chemistry because of the demands of the degree schemes they would like to follow. Hence, chemical education certainly demands more attention to be given to a greater diversity of activities and skills such as mainly numeracy experimental work. A didactic approach may well prove useful in attempting to increase the popularity of the discipline amongst students. Indeed, in this study about $36.9 \%$ of students in the two groups thought that Chemistry is an interesting subject and $52.8 \%$ of respondents believed that Chemistry is not a boring subject. However, there is a consensus that Chemistry is a disfavoured option for various careers compared to other subjects, like Maths, English, Business and other social subjects. Some studies suggest that students entering college no longer perceive physical sciences, such as Chemistry to be either desirable or achievable as career aspirations [14]. This notion may support responses to the following statement: I considered taking Chemistry for a future career (2D), where $64.7 \%$ of AS Chemistry students.

Furthermore, the results have indicated that the help students may receive from home, teacher or school may contribute to increase student's interest in Chemistry. Indeed these features are not separate entities in themselves. These factors can be seen as corresponding directly to yield the increased interest given. For example, an individual who is attracted to the field through positive role models is more likely to consider Chemistry as a career and thus be further interested in the field.

There are various factors that contribute to the image of Chemistry as a discipline. Organic plant products, a 'chemical-free garden and other terms that are frequently used for advertisement purposes may contribute inversely to chemical education. Furthermore, it has become apparent that chemicals are dangerous whether because of toxicity, flammability or some adverse effects on the environment, which may participate in the association of the public that Chemistry is dangerous. All these factors may contribute to chemical education declining [2].

In conclusion although the number of respondents was only 36 , the statistical analysis and the overall results have highlighted some important factors that are associated with student's preferences in chemical education.

Table 7. Chi-square results of statements that showed statistical differences

\begin{tabular}{|c|c|c|c|}
\hline Statement & Chi-Square & DF & Sig. (2-sided)* \\
\hline Chemistry is a difficult subject (2A) & 12.104 & 2 & 0.002 \\
\hline Chemistry is an interesting subject (3A) & 13.252 & 2 & 0.001 \\
\hline The mathematics involved makes it not easy to understand (4A) & 7.757 & 2 & 0.021 \\
\hline The practical part of a Chemistry lesson encouraged me to take it (6A & 13.694 & 2 & 0.001 \\
\hline Chemistry is a challenging subject that is why I like it (7A) & 11.854 & 2 & 0.003 \\
\hline Chemistry is a boring subject that is why I do not like it (8A) & 11.359 & 2 & 0.003 \\
\hline It is not easy to select, organize and present chemical information clearly and logically (4B) & 16.680 & 2 & 0.000 \\
\hline Explaining and interpreting chemical principles and concepts are not easy (1C) & 9.423 & 2 & 0.009 \\
\hline It is complicated to make connections between different topics (4C) & 16.590 & 2 & 0.000 \\
\hline I considered taking Chemistry because there will be help offered at home (1D) & 13.418 & 2 & 0.001 \\
\hline
\end{tabular}

\section{References}

[1] De Jong, O. Crossing the borders: Chemical education research and teaching practice Processing. U. Chem. Ed. 4, 2000.

[2] Breuer S.W. Does Chemistry have a future? U. Chem. Ed. 6, 1316, 2002.

[3] William S. Price and John O. Hill. Raising the Status of Chemistry Education. U. Chem. Ed. 8 (1), 13-20, 2004.

[4] I was never any good at Chemistry; I never understood atoms and molecules; I enjoyed splashing about in the laboratory, but I did not understand what I was doing p. 34.

[5] Reece, I. and Walker, S. Teaching, training and learning: A practical guide. 5th Ed., Business Education Publishers Limited, Great Britain, 2003.

[6] Festus, C. Improving Students' Performance and Attitude towards Chemistry through Problem-Based-Solving Techniques (PBST). Inter. J. Academic Res. in Progressive Education and Develop. January, 1 (1), 167-174, 2012.

[7] Bransford, J.D., Brown, AL. and Cocking, R.R. How to learn. National $\quad$ Research 1999. http://newton.nap.edu/html/howpeople1/es.html [Accessed 20/3/2006].
[8] Burewicz, A. and Miranowicz, M. Individualisation of student's tasks in blended learning course of information technology for chemists with dynamic instructions. Recent Research Developments in Learning Technologies, 2005. http://www.formatex.org/micte2005/339.pdf. [Accessed 20/3/2006].

[9] Bretz, S.L. Human Constructivism and Meaningful learning, Online Symposium: Piaget, constructivism, and beyond. J. Chem. Educ, 78, 1107, 2001.

[10] Gunter, B. Media Research Methods. London: Sage Publications, 2000.

[11] Oppenheim, A.N. Questionnaire design and attitude measurement, London: Printer, 1992.

[12] Cohen, L. and Manion, L. Research Methods in Education. (4th ed.). London: Routledge, 1995.

[13] Hughes, M. Comparative educational administration. In N. J. Boya (ed.). Handbook of Research on Educational Administration: a project of the American Educational Research Association. New York: Longman, 1988.

[14] Doyle, M. The Value of Research in Undergraduate Chemistry education,

2006. http://urc.arizona.edu/The\%20Value\%20of\%20Research\%20inUn dergraduate\%20Chemistry\%20Education.cfm [Accessed 20/3/2006]. 